\title{
Health safety on plastic materials that come into contact with food and children toys about migration of primary aromatic amines examination in IPH- Skopje in period $01.012013-31.12 .2013$
}

\author{
Evgenija Kiroska-Petreska ${ }^{1}$, Katja Popovska ${ }^{2}$, Dragan Gjorgjev ${ }^{1}$, Vesna Kostikj ${ }^{1}$, \\ Branka Petrovska ${ }^{1}$ \\ ${ }^{1}$ Institute for Public Health of Republic of Macedonia, Skopje, Republic of Macedonia \\ ${ }^{2}$ Institute of Microbiology and parasitology, Faculty of Medicine, University “Ss Cyril and Methodius”, Skopje, Republic of Macedonia
}

\section{Email address:}

ekakp@yahoo.com (E. Kiroska-Petreska)

\section{To cite this article:}

Evgenija Kiroska-Petreska, Katja Popovska, Dragan Gjorgjev, Vesna Kostikj, Branka Petrovska. Health Safety on Plastic Materials that Come into Contact with Food and Children Toys about Migration of Primary Aromatic Amines Examination in IPH- Skopje in Period 01.012013 - 31.12.2013. Journal of Food and Nutrition Sciences. Vol. 2, No. 3, 2014, pp. 63-67. doi: 10.11648/j.jfns.20140203.13

\begin{abstract}
Backgorund: Humans can be exposed to primary aromatic amines (PAAs) by the usage of a variety of synthetic products which come in contact with food and plastic children toys. PAAs are mainly originated from synthetic azo dyes widely applied as colorants on plastics and also from the use of adhesives based on polyurethanes (PU) in laminated food packing materials. Legislation introduced in the European Union countries limiting the migration level of PAAs into foodstuffs is $0.01 \mathrm{mg} / \mathrm{kg}$. Aim: To establishing method for routine examination of PAAs in items made of plastics that come into direct contact with food and plastic toys. Material and Methods: Quantitative determination of sum of PAAs, expressed as aniline on 727 items of which 363 plastic toys, and 364 plastic containers, plastic utensils and plastic items that come in direct contact with food. Was using spectrophotometric method based on diazotisation of PAAs and subsequent coupling of the obtained diazonium salts with N-(1-naphthyl) ethylenediamine dihydrochloride. Resultes: Calibration was carried out using known amounts of aniline hydrochloride as standard. Detection limit (DL) and quantification limit (QL) evaluated for direct spectrophotometric method amounted to 0,000715 mg/l and 0,002165 mg/l, respectively. Only 6 tested samples were not correct in terms of increased concentration of PAAs in simulant solution. From the faulty samples 4 were toys, and 2 black kitchen sets which coming in contact with food. Conclusion: Requires increased sanitary inspection market, amid frequent occurrence of PAAs in plastic kitchen utensils, especially kitchen utensils in black and children toys made in China.
\end{abstract}

Keywords: Food Contact Materials (FCM), Toys, Primary Aromatic Amines (PAAs), Migration, Safety

\section{Background}

The most common types of materials that come in direct contact with food materials made of plastic or plastic containers. [1,2] Plastics are defined as processed material made from polymers. [3,4] The term plastic means macromolecular organic chemical compounds obtained by: polymerization, polycondensation, polyaddition or other similar process, or by low molecular weight substances by chemical modification of natural macromolecules (Directive 2002/72/EC). [5] In such macromolecular chemical compounds can be added to other substances or materials. An important factor, which does not take sufficient account when selecting the type of plastic material for certain foods (acidic, fatty and neutral), is the inertia of the polymer, which depends on the transmission (diffusion) of substances in food. If the material is more inert and chemical hazard in terms of migration of toxic substances in food will be less. [6] This is especially important in case of recycled materials, which should be especially careful. [7]

The primary aromatic amines (PAA) are commercially available since the mid 1800s. They are widely used in various branches of the chemical industry. Amines introduced into the human body can cause carcinogenic 
processes. People can be exposed to PAA using different synthesized products. [8] Exposure to aniline emphasizes the creation of metabolite - phenyl hydroxylamine, which damages the hemoglobin, which is responsible for transporting oxygen in the bloodstream, which damaged protein cannot transport oxygen is put together for aniline and causes methemoglobinemia, which is result of poisoning with aniline. Bladder cancer is also associated with aniline. [9] In industrialized cities of bladder cancer is the fifth in matching and appearance for women is three times less. Lately interest in human exposure to PAAs through their migration from packaging into food is very high. [10] Primary aromatic amines are generated by reaction of the free non-reactive monomers isocyanates with water, which is present in certain foods. If the monomer is soluble in water, then the water will react with isocyanates as a secondary alcohol, where the hydrolysis reaction will occur related volatile compounds that release $\mathrm{CO}_{2}$ and thereby create primary aromatic amines according to equation:

$$
\mathrm{RNCO}+\mathrm{H}_{2} \mathrm{O}=(\mathrm{RNHCOOH})=\mathrm{RNH}_{2}+\mathrm{CO}_{2}
$$

Azo-dyes are used as black pigment or colorant for nylon, the production of objects and materials that come in direct contact with food (kitchen ladles and other utensils for food) and also a possible migration of PAAs (especially 4,4-methylene dianiline) in food.

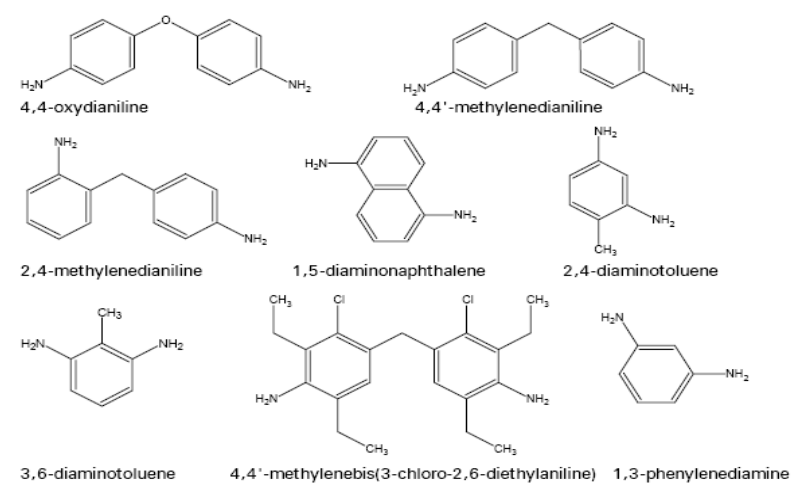

Figure 1. Important primary aromatic amines.

The problem with the occurrence of PAAs coated in plastic packaging derived from the use of adhesive means (for bonding), based mostly on polyurethane (PU), which are used for bonding of multilayered coatings.

The temperature and time of immersion should show real contact with food subject. The temperature and time of immersion as parameters to match the actual conditions in practical application. Spectrophotometric method based diazotation of PAAs and further their pairing for the diazonium salt with N-(1-naphthyl) ethylenediamine dihydrochloride, is recommended as the first step to detect the PAAs migration solutions. In the determination of the PAAs migration of objects with spectrophotometric method, calibration is performed by known quantities of standardaniline hydrochloride $\left(\mathrm{C}_{6} \mathrm{H}_{5} \mathrm{NH}_{2} \times \mathrm{HCl}\right)$. An estimate of the amount of PAAs is expressed as the amount of aniline. The procedure allows the determination of the amount of PAAs, which migrate from the test material simulant solution. This method cannot identify specific migratory groups. Chromatography GC/MS and HPLC techniques can be used for specific detection of certain amines. [11]

\section{Aim of the Study}

The aim of this paper is to establishing method for routine examination of primary aromatic amines in items made of plastics that come into direct contact with food and plastic toys, and in accordance with the requirements of European and national legislation. [12]

To achieve the stated objective, the following tasks:

1. Establishing a spectrophotometric method with visible (VIS) detection, for quantitative determination of primary aromatic amines (PAAs), expressed as aniline with optimization and validation of the proposed method.

2. Determination of primary aromatic amines (PAAs) in plastic items that come in contact with food and plastic toys in IPH RM- Skopje, in period 01.01.2013 - 31.12.2013.

\section{Methology}

Items that come in direct contact with food should be washed with hot water and detergent containers, and with distilled water and left to dry. Plastic toys do not wash out. Appropriate area $\left(\mathrm{dm}^{2}\right)$ of the object or material that comes in contact with food is immersed in a certain volume $(\mathrm{ml})$ of simulant solution ( $3 \%$ acetic acid). The samples, which are not possible to accurately determine the surface, apply the following equation:

$1 \mathrm{~kg}$ simulant solution $(1 \mathrm{~L})=6 \mathrm{dm}^{2}$ of the surface of the object / material

Objects and materials are immersed in $170 \mathrm{ml}$ solution simulant at exactly the prescribed temperature at a specified time (10 days at $22 \pm 2^{\circ} \mathrm{C}$ or 2 hours at $70^{\circ} \mathrm{C}$ or 10 days at $40^{\circ} \mathrm{C}$ ). At the appointed time for immersion, the sample is removed from simulant solution, and the resulting extract is used for testing the specific migration of PAAs.

\subsection{Materials}

727 items of which 363 were plastic toys and 364 were plastic containers, plastic utensils and plastic items that come in direct contact with food.

\subsection{Apparatus and Laboratory Supplies}

- $\quad$ Spectrophotometer Lambda 12, Perkin Elmer, USA;

- $\quad$ Glass cells than $1 \mathrm{~cm}$;

- $\quad$ Zucchini of $10 \mathrm{ml}, 25 \mathrm{ml}, 100 \mathrm{ml}$ and $1000 \mathrm{ml}$;

- Pipettes from 1,0 ml; 2,0 ml, $5 \mathrm{ml}$ and 10,0 ml (Aclass); 
- Electrical Scales Sartorius BP-110 S, Germany;

- Other laboratory equipment.

\subsection{Reagents}

- Aniline hydrochloride $\left(\mathrm{C}_{6} \mathrm{H}_{5} \mathrm{NH}_{2} \quad \mathrm{x} \quad \mathrm{HCl}\right)$ Sigma Aldrich, Germany;

- $\quad$ Chloride acid ( $\mathrm{HCl})$ pr.37\%, pa Merck, Germany;

- Sodium nitrite $\left(\mathrm{NaNO}_{2}\right)$ pr:> 99\%, pa Sigma Aldrich, Germany;

- Ammonium amidosulfamate $\left(\mathrm{NH}_{4} \mathrm{SO}_{3} \mathrm{NH}_{2}\right)$ pr: $>98 \%$, Sigma Aldrich, Germany;

- N-(1-naphthyl) ethylenediamine dihydrochloride $\left(\mathrm{C}_{10} \mathrm{H}_{7} \mathrm{NHCH}_{2} \mathrm{CH}_{2} \mathrm{NH}_{2}\right.$ x 2HCl),pr:> 98\%, Sigma Aldrich, Germany;

- Glacial acetic acid $\left(\mathrm{CH}_{3} \mathrm{COOH}\right)$ pr. $>$ 99,8\%, pa Merck, Germany.

\subsection{Analitycal Prodedure}

$1 \mathrm{dm}^{2}$ of the material or object that comes in contact with food is immersed in a certain volume $(170 \mathrm{ml})$ of solution simulant $3 \%$ acetic acid, at exactly the prescribed temperature at a specified time (10 days at $22 \pm 2^{\circ} \mathrm{C}$, or 2 hours at $70^{\circ} \mathrm{C}$ or 10 days at $40^{\circ} \mathrm{C}$ ). After the time limit for immersion, the sample is removed from the solution simulant. The resulting extract is used to examine the specific migration of PAA. $10 \mathrm{ml}$ of the extract is transferred to the zucchini of $25 \mathrm{ml}$, mixed with $5 \mathrm{ml} 1 \mathrm{M} \mathrm{HCL}$ and $1 \mathrm{ml}$ $\mathrm{NaNO}_{2}$ and placed to stand $10 \mathrm{~min}$. Then add $2 \mathrm{ml} \mathrm{2,5 \%}$ solution of ammonium amidosulfamate to neutralize excess $\mathrm{NaNO}_{2}$, vigorously mixed and left to stand for another 10 min. After these $10 \mathrm{~min}$ add $2 \mathrm{ml} \mathrm{1 \%}$ solution of $\mathrm{N}-(1$ naphthyl) ethylenediamine dihydrochloride and added to distilled water to the mark and mix vigorously. Courgettes are put to soak about 30 minutes, until the appearance of redviolet coloration. Spectrophotometric measuring on wavelength, $\lambda=557 \mathrm{~nm}$ is performed within 2 hours after the staining reaction in relation to the blank. $[13,14]$.

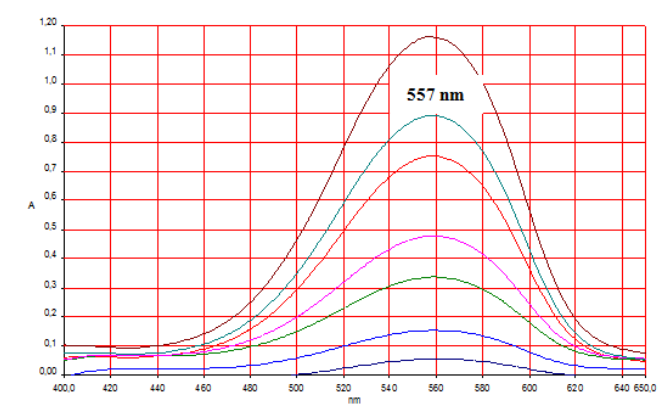

Figure 2. Spectral distribution of standard solutions of aniline hydrochloride in 3\% acetic acid with concentration of 0,01-0.8 mg/l, in the visible spectar of 400-650 $\mathrm{nm}$ with a maximum at absorbance $557 \mathrm{~nm}$.

The amount of PAA is calculated according to:

$$
\mathrm{M}_{\mathrm{S}}=\mathrm{a} \times \mathrm{c} / 10 \times \mathrm{b}=\mathrm{mg} / \mathrm{dm}^{2},
$$

Where:
MS - specific migration of primary aromatic amines (expressed as aniline) in $\mathrm{mg} / \mathrm{dm}^{2}$.

a. Apsorbtion/concentration of aniline hydrochloride/aniline, using a spectrophotometer.

b. Surface material or object in $\mathrm{dm}^{2}$, which was in direct contact with the appropriate solution.

c. simulant volume of solution in $\mathrm{ml}$.

Specific migration of PAAs can be expressed as aniline or aniline hydrochloride, the correction relations relative molecular masses: $\mathrm{Mr}\left(\mathrm{C}_{6} \mathrm{H}_{5} \mathrm{NH}_{2}\right)=93,13 \mathrm{~g} / \mathrm{mol}$ and $\mathrm{Mr}$ $\left(\mathrm{C}_{6} \mathrm{H}_{5} \mathrm{NH}_{2} \times \mathrm{HCl}\right)=129,59 \mathrm{~g} / \mathrm{mol}$.

\section{Results}

The range of the method is the interval between the highest and lowest limit of the analyzed substances validated in terms of linearity, accuracy and precision of the analytical method. During the validation of the method for determination of PAAs, expressed as aniline, the range is determined in the linearity test. The calibration curve of aniline, obtained by the regression of rights presented in Figure 3, one can see that it is linear $(y=1.4066 \mathrm{x}-0.0058$, $\left.\mathrm{R}^{2}=0,9999\right)$, in the tested area of $0,01 \mathrm{mg} / 1$ to $0,8 \mathrm{mg} / 1$.

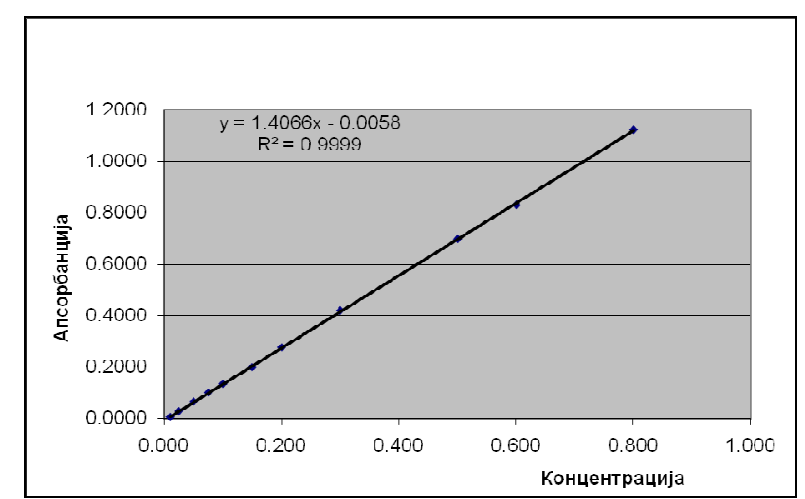

Figure 3. Calibration curve of aniline hydrochloride in 3\% acetic acid.

The value of the correlation coefficient $\left(R^{2}=0,9995\right)$ indicates a high degree of linear dependence of absorption and concentration in the examined concentration range from $50 \%$ to $200 \%{ }^{1}$. [15]

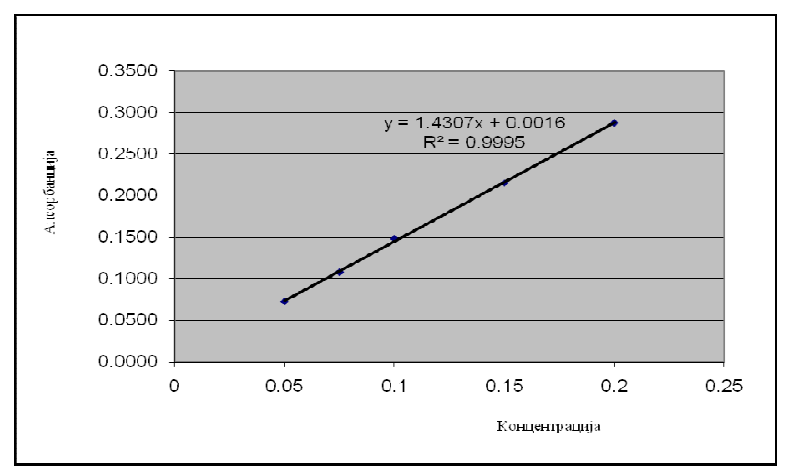

Figure 4. Calibration curve of aniline hydrochloride in $3 \%$ acetic acid in concentrations of $50 \%$ to $200 \%$ compared to the working concentration $(0,1 \mathrm{mg} / \mathrm{l})$. 
The limit of detection is the lowest concentration of the analyzed substance that can be detected and the limit of quantification is the lowest concentration of the analyzed substance that can be quantified with acceptable accuracy and precision. Standard solutions of aniline hydrochloride are prepared in $3 \%$ acetic acid with concentrations: 0,010 $\mathrm{mg} / \mathrm{l} ; 0,012 \mathrm{mg} / 1 ; 0,014 \mathrm{mg} / 1 ; 0,016 \mathrm{mg} / 1 ; 0,018 \mathrm{mg} / 1$ and $0,020 \mathrm{mg} / 1$. Absorption measured and calculated the mean. From the values of the equation of rights is calculated boundary limit of detection (LoD) and limit of quantification (LoQ), According to the following equation:

$$
\begin{aligned}
& \mathrm{LoD}=3,3 \cdot \mathrm{STExy} / \mathrm{a} \\
& \mathrm{LoQ}=10 \bullet \mathrm{STExy} / \mathrm{a}
\end{aligned}
$$

The results of our tests for LoD and LoQ, the lowest concentration of aniline, which can be detected is $0,7 \mathrm{ng} /$ $\mathrm{ml}$, and the lowest concentration that can be determined is $2,1 \mathrm{ng} / \mathrm{ml}$. [16]

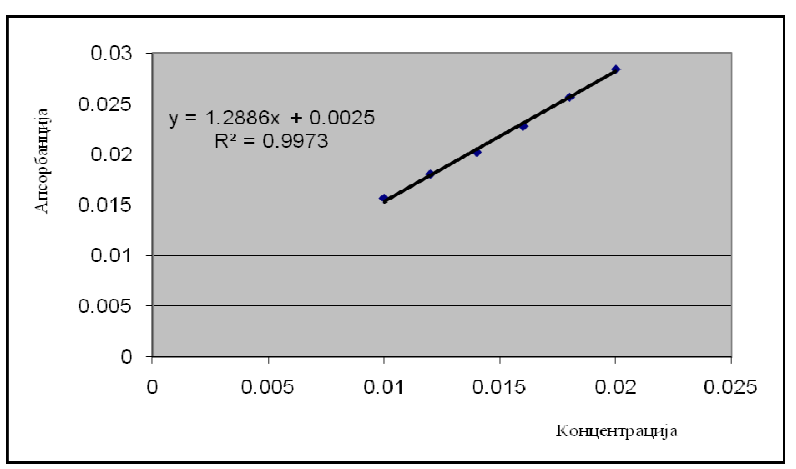

Figure 5. Calibration curve standard solutions of aniline hydrochloride in $3 \%$ acetic acid concentrations: 0.01, 0.012, 0.014, 0.016, 0.018 and 0,02 $\mathrm{mg} / \mathrm{l}$ for determination of linearity and calculate the LoD and $L O Q$.

\section{Discussion}

In routine laboratory tests of PAAs, commonly used spectrophotometric methods. The application of these methods for determining the amount of PAAs in items made of plastic materials that come in contact with food and toys made of plastic is economically justified in terms of cost of apparatus and chemicals.

We did our testing of this modification spectrophotometric method in order for it to apply for fast determination (screening) of the total amount of PAAs, expressed as aniline, not individually for each amine. Used $1 \mathrm{M} \mathrm{HCl}$ and $0,5 \% \mathrm{NaNO}_{2}$, since PAAs is reacted in acid medium to form with nitritnite ions, diazonium salt in the reaction with $1 \% \quad \mathrm{~N}$-(1-naphthyl) ethylenediamine dihydrochloride and form colored compounds, with characteristic intensivy violet coloration, the intensity of is proportional to the concentration of PAAs in the test solution.

In period from 01.01.2013 - 31.12.2013 in Laboratory testing for health safety of the items for general use in Institute for Public health of R. Macedonia was performed spectrophotometric testing 727 samples of PAAs: 363 plastic toys and 364 plastic items that come in contact with food and plastic packaging. Only 6 tested samples were not correct in terms of increased concentration of PAAs in simulant solution. From the faulty samples 4 were toys, and 2 black kitchen sets which coming in contact with food.

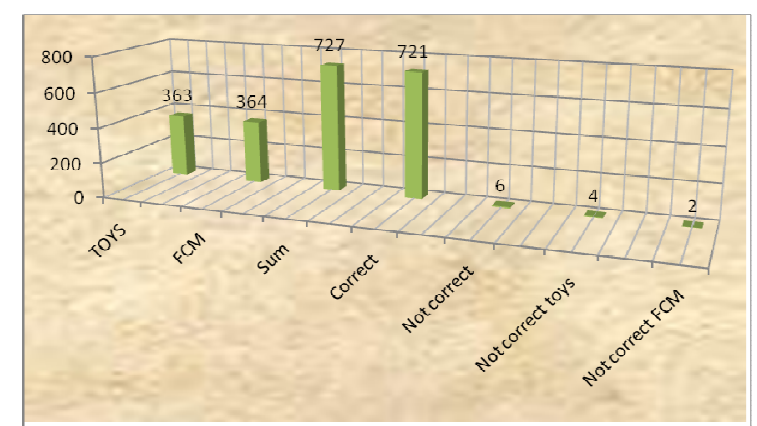

Figure 6. Testing samples about PAAs in 2013.

\section{Conclusion}

Based on the obtained results it can be concluded that the applied spectrophotometric method can be used for routine testing of primary aromatic amines in items made of plastics that come into direct contact with food and plastic toys, which is confirmed and the purpose of this labor.

From tested 727 samples about PAAs (method from:"Amtliche Sammlung von Untersuchungsverfahren nach § 35 LMBG L 00.00-6) [17], expressed as aniline, only 6 exceeded SML $=0.01 \mathrm{mg} / \mathrm{kg}$. The occurrence of potentially toxic compounds, like PAAs in food contact packaging may cause problems to health of consumers. Requires increased sanitary inspection market, amid frequent occurrence of PAAs in plastic kitchen utensils, especially kitchen utensils in black and children toys made in China.

\section{References}

[1] Castle L. (2000). An Introduction to Chemical migration from Food Contact Materials. International Food Safety News (9), 2-4.

[2] Castle L. (2000) Chemical migration from food packaging. :U Food chemical safety-Volume 1 Contaminants (Watson D. H. ured.), CRC Press LLC, Boston str. 193-217.

[3] Franz R.; Stormer A. (2008) Migration of Plastic Constituens. U: Plastic Packaging- Second Edition (Baner A., Piringer O., ured.), Weinheim: Wiley-VCH, Verlag GmbH \&Co., str. 349-417.

[4] Directive 2002/72/EC. Commission Directive of 6 August 2002 relating to plastic materials and articles intended to come into contact with foodstuffs (09.11.2009). Official Journal of the European Union L 072 (2009) p. 006.001-1 006.001-78.

[5] Morrison R.T., Boyd R.N. (1992) Organic Chemistry, 6.izd., Prentice Hall, New Jersey 
[6] Petersen, J. (2003) Migration of Compounds from Food Contact Materials and Articles. U: j., Food Safety: Contaminants and Toxins, (D'Mello F.P.J.,ured.), CAB International, Edinburgh, str. 271-292.

[7] Leber A.P. (2001) Human exposures to monomers resulting from consumer contact with polymers. Chemico-Biological Interactions , 135-136, 215-220.

[8] Muncke J. (2009) Exposure to endocrine disrupting compounds via the food chain: Is packaging a relevant source? Science of the Total Environment, 407 (16), 4549-4559.

[9] Vergnaud J.M. (1998). Problems encountered for food safety with polymer packages: chemical exchange, recycling. Advances in Colloid and Interface Science, 78 (3), 267-29796979899.

[10] Bustos J.,Sendón J.,Sánchez J.J.,Paseiro P.,Cirugeda M.E. (2009) Migration of $\varepsilon$-caprolactam from nylon cooking utensils: validation of a liquid chromatography-ultraviolet detection method. European Food Research and Technology, $230(2), 303-313$

[11] W.Kolado and M.Balcerzak The examination of migration of primary aromatic amines from laminated plastic food packaging materials into food stimulants by spectrofotometric method. Acta Alimetaria, Vol.38(1), pp. 45-54 (2009)
[12] Commision Regulation (EU) No 10/2011 on plastic materials and articles intended to come into contact with food

[13] Danish Institute for Food and Veterinary Research (DFVF). (2004) Memorandum for the Danish Veterinary and Food Administration: Subject: An acute case of primary aromatic amines migrating from cooking utensils. Danish Institute for Food and Veterinary Research (DFVF), Dennmark.

[14] Validation of Analytical Procedure, Methodology, Step 4, Consennsus, ICH Harmonised Tripartite Guideline, ICH Topic Q2(R1) (2005)

[15] Validation of Analytical Methods, Definition and Terminology, ICH Harmonised Tripartite Guideline, ICH Topic Q2(R1) (2005)

[16] Perharic L.,Golja V., Zoric A., Luci M. (2006) Primary aromatic amines in kitchen utensils in Slovenia. Toxicology Letters, 164, 278-279.

[17] The measurement of PAAs in aqua food stimulants. Amtliche Sammlung von Untersuchungsverfahren nach $\S 35$ LMBG (Lebensmittel- und Bedarfsgegen ständegesetz)", part 1/1, L 00.00-6, Beuth Berlag GmbH, Berlin, Koln, (1990). 